\title{
CORRIGENDUM
}

\section{White Matter Microstructural Integrity and Executive Function in Parkinson's Disease - CORRIGENDUM}

C. Gallagher, B. Bell, B. Bendlin, M. Palotti, O. Okonkwo, A. Sodi, R. Wong, L. Buyan-Dent, S. Johnson, A. Willette, S. Harding, AND A. Alexander

doi:10.1017/S1355617712001373, Published by Cambridge University Press, 15 January 2013.

In "White Matter Microstructural Integrity and Executive Function in Parkinson's Disease," one of the coauthors names was published incorrectly. Auriel Wilette should read: Auriel Willette. The authors regret the error.

\section{REFERENCE}

Gallagher, C., Bell, B., Bendlin, B., Palotti, M., Okonkwo, O., Sodi, A., et al. (2013). White Matter Microstructural Integrity and Executive Function in Parkinson's Disease. International of the Journal Neuropyschological Society, 19(3), 349-354. doi: $10.1017 /$ S1355617712001373. 